\title{
Comparison of clinical outcomes between sentinel lymph node biopsy and axillary lymph node dissection in a single-center Z0011-eligible breast cancer cohort
}

Heein Jo, Eun-Gyeong Lee, Eunjin Song, Jai Hong Han, So-Youn Jung, Han-Sung Kang, Eun Sook Lee, Seeyoun Lee Department of Surgery, Center for Breast Cancer, National Cancer Center, Goyang, Korea

Purpose: The ACOSOG Z0011 trial has proven the oncological safety of sentinel lymph node biopsy (SLBX) for node negative breast cancer. Accordingly, treatment paradigm including axilla surgery was changed. We retrospectively reviewed breast cancer patients to evaluate the clinical effect of paradigm shift in breast cancer surgery after applying the Z0011 criteria.

Methods: All women who underwent breast-conserving surgery at the National Cancer Center between January 1, 2000, and December 31, 2015, were enrolled and classified according to the Z0011 criteria. The primary endpoint of the study was the disease-free survival rates, and the secondary was the adverse events, especially arm lymphedema.

Results: Total 361 patients were enrolled the study (271 axillary lymph node dissection [ALND] group, 90 SLBx group). After the Z0011 guideline was adopted in our institute, the use of ALND decreased, and lymph node sampling (removing only a few axillary lymph nodes) replaced ALND. The total mean number of retrieved nodes were more in ALND group (13.02) than SLBx group (3.43). However, there was no difference in the mean number of positive nodes between two groups (2.34 in ALND group vs. 1.12 in SLBx group, $\mathrm{P}=0.001$ ). During follow-up, 25 patients experienced disease recurrence: 22 from the ALND group and three from the SLBx group. All of died seven patients were from the ALND group. The ALND group had more complications than the $\operatorname{SLBx}$ group $(P=0.02)$. Arm edema occurred more frequently in the ALND group (29.5\%) than in the SLBx group (5.6\%), although without statistical significance $(P=0.07)$.

Conclusion: In our study, we concluded that SLBx can be used safely in Z0011-eligible cohort without increased risk of locoregional recurrence. Moreover, we found that omission of ALND is favored to reduce some serious complications such as arm lymphedema.

Keywords: Breast neoplasms, Breast cancer lymphedema, Sentinel lymph node biopsy, Breast conserving surgery

Received: Feb 12, 2020 Revised: Jun 11, 2020 Accepted: Jun 22, 2020

Correspondence to: Seeyoun Lee

Department of Surgery, Center for Breast Cancer, National Cancer Center, 323 Ilsan-ro, Ilsandong-gu, Goyang 10408, Korea

Tel: +82-31-920-1736, Fax: 82-31-920-1759

E-mail: seeyoun@ncc.re.kr

ORCID: Heein Jo (https://orcid.org/0000-0002-0521-031X), Eun-Gyeong Lee (https://orcid.org/0000-0002-5345-8846), Eunjin Song (https://orcid.org/00000003-3114-6953), Jai Hong Han (https://orcid.org/0000-0003-3703-854X), SoYoun Jung (https://orcid.org/0000-0002-4508-4522), Han-Sung Kang (https:// orcid.org/0000-0002-0609-4293), Eun Sook Lee (https://orcid.org/0000-00031122-8230), Seeyoun Lee (https://orcid.org/0000-0002-7576-1512)

Copyright ( 92020 Korean Society of Surgical Oncology

This is an Open Access article distributed under the terms of the Creative Commons Attribution Non-Commercial License (http://creativecommons.org/licenses/by-nc/4.0) which permits unrestricted non-commercial use, distribution, and reproduction in any medium, provided the original work is properly cited.

\section{INTRODUCTION}

The use of sentinel lymph node biopsy (SLBx) instead of traditional axillary lymph node dissection (ALND) was proven to be an efficacious and safe local therapy for node-positive breast cancer by the 2010 ACOSOG Z0011 trial [1,2]. National Comprehensive Cancer Network guidelines have been changed to reflect this study. In 2017, a 10-year follow-up of the Z0011 trial was published [3]. There was no difference in overall or progression-free survival between the SLBx only group and the ALND group in this follow-up study.

After the Z0011 criteria were published, several multifaceted approaches were taken to verify that the criteria could be applied safely. A study in Canada compared cases that met the Z0011 criteria as classified into three groups (before Z0011 publication, after publication, and after guideline dissemination) and found that the proportion of patients undergoing ALND gradually decreased 
( $82 \%$ before publication, $58 \%$ after publication, and $39 \%$ after guideline dissemination) [4]. More than $80 \%$ of patients in the Z0011 trial were hormone receptor-positive. Another study evaluated patients with high-risk breast cancer (triple negative or human epidermal growth factor receptor 2 [HER2] positive breast cancer or diagnosed before the age of 40 years). There was no difference in survival rate between ALND and SLBx only groups in high-risk breast cancer patients. It was concluded that Z0011 criteria could be safely applied in high-risk breast cancer [5]. This approach has precedence in Korea through multicenter studies. In 2014, investigators evaluated the effect of SLBx and ALND on survival rate in cases of T1, T2, and node-positive patients. A total of 2,581 patients were enrolled from January 2001 to April 2011 in 110 hospitals. Adding ALND after SLBx did not improve the overall survival rate [6]. Another study from 2010 to 2016 in five hospitals compared ALND with SLBx only in a Z0011-eligible cohort of 1,750 patients with one or two sentinel lymph node metastases. This study confirmed that the omission of ALND does not increase the risk of breast cancer recurrence [7].

National Cancer Center of Korea has adopted and applied the Z0011 criteria from 2012. We retrospectively reviewed all breast cancer surgeries performed since the National Cancer Center began conducting operations for breast cancer. This study illuminates the effect of a paradigm shift in axillary surgery for breast cancer management after the application of Z0011 criteria. Furthermore, we hypothesized that omission of ALND would not affect the local recurrence rate and overall survival in cases within a Z0011-eligible cohort. We demonstrate the safety of applying SLBx over ALND in Z0011-eligible patients, and show that omission of ALND may reduce the incidence of serious complications.

\section{METHODS}

\section{Inclusion criteria}

All women who underwent surgery for breast cancer at the National Cancer Center between January 1, 2000 and December 31, 2015, were enrolled and classified according to the Z0011 criteria. A total of 361 patients were enrolled in the study. The need for obtaining patients' informed consent was waived off due to the retrospective nature of the study.

\section{Exclusion criteria}

The following cases were excluded: those converted to mastectomy, those receiving neoadjuvant chemotherapy, those having discontinued or not received postoperative chemotherapy or radiotherapy, those where surgery for recurrent breast cancer occurred, those with tumors $\geq 5 \mathrm{~cm}$, and those with carcinoma in situ.

\section{Data extraction}

Clinical data on surgery and postoperative therapy and follow-up records were retrospectively collected from electronic medical records.

\section{Demographic data}

Sex, age at diagnosis, clinical nodal stage, tumor location, type of postoperative chemotherapy, and type of postoperative targeted or hormonal therapy (if applicable) were recorded for all patients. Clinical nodal stage was determined according to pathologic review of preoperative lymph node imaging (mammogram, breast magnetic resonance imaging, breast sonography, positron-emission tomography/computed tomography [CT], chest CT). If one or more imaging modalities showed a suspicious lymph node, it was considered to be positive and excluded from the study.

\section{Operation-related factors}

Date of surgery, type of axilla operation, number of retrieved nodes (sentinel/total), and number of positive nodes (sentinel/total) were recorded for all patients. Axilla node sampling is defined as a case in which a sentinel lymph node is manually removed without dissecting axillary lymph nodes when the frozen biopsy is tumor positive. In cases of ALND, the extent of dissection was not included in the study.

\section{Outcome-related factors}

Last follow-up date, date of death, and date of recurrence were collected through electronic medical records. Last follow-up date was defined as the last outpatient visit for assessment of the affected breast between the operation date to June 30, 2019. We classified recurrence as either locoregional or distant. Postoperative complications were classified as bleeding, wound infection, seroma, arm edema, or axillary web syndrome. Arm edema was defined by the need for therapy for edema in our rehabilitation clinic. If patients were treated over one year after surgery, we designated it as "persistent edema." "Transient edema" was defined as the need for treatment being limited to less than one year after surgery.

\section{Statistical analyses}

To confirm clinical significance, we divided the patients into two groups depending on whether they had axillary dissection or not (SLBx group vs. ALND group). SLBx group contained in case of SLBx only and/or additional sampling. The primary endpoint of this study was to evaluate the difference in disease-free survival rate between the SLBx group and ALND group. The secondary outcome measures were differences in adverse events between the SLBx group and ALND group, especially the aspect of arm lymph- 
edema. SPSS version 27.0 (IBM Corp., Armonk, NY, USA) was used to compare the difference between the SLBx group and the ALND group among patients meeting the Z0011 criteria.

To compare the incidence of surgical complications between the SLBx group and ALND group, we used a chi-square test. Disease-free survival rates were assessed by Kaplan-Meier survival curve methodology with a $\mathrm{P}<0.05$ significance threshold. Additionally, to identify affecting recurrence, we used a logistic regression method.

\section{RESULTS}

\section{Clinicopathological findings}

We divided patients between two groups (SLBx group and ALND group). The mean age at diagnosis of all patients was 48.78 years. Consistent with the well-known epidemiology of breast cancer, there was a concentration of patients aged 40 to 49 years. Clinical characteristics were similar between groups (Table 1 ).

About half of the patients had stage-T2 disease. N1a was the most frequent nodal stage. Of the hormone therapies, tamoxifen was the most commonly used. Twenty-eight patients received hormone therapy with combined selective estrogen receptor modulator and aromatase inhibitor to reduce adverse effects, with two patients discontinuing hormone therapy during the course of treatment. In addition, 10 of the patients who were indicated for trastuzumab therapy did not receive targeted therapy for economic reasons.

\section{Operation data}

The mean number of retrieved nodes was 13.02 in the ALND group compared to 3.43 in the SLBx group $(\mathrm{P}=0.25)$. However, there was no difference in the mean number of positive sentinel nodes among the groups (Table 2).

Fig. 1. demonstrates the change in paradigm for axillary operation in breast cancer. After the Z0011 guideline was disseminated

Table 1. Clinicopathological data

\begin{tabular}{lccc}
\hline Variable & $\begin{array}{c}\text { Total } \\
(n=361)\end{array}$ & $\begin{array}{c}\text { SLBx group } \\
(n=90)\end{array}$ & $\begin{array}{c}\text { ALND } \\
(\mathrm{n}=271)\end{array}$ \\
\hline Age at diagnosis (yr) & $48.78 \pm 9.23(31-81)$ & & \\
$30-39$ & $50(13.8)$ & $15(16.7)$ & $35(12.9)$ \\
$40-49$ & $156(43.2)$ & $40(44.4)$ & $116(42.8)$ \\
$50-59$ & $109(30.1)$ & $22(24.4)$ & $87(32.1)$ \\
$60-69$ & $33(9.1)$ & $9(10.0)$ & $24(8.8)$ \\
$70-79$ & $12(3.3)$ & $4(4.4)$ & $8(2.9)$ \\
$\geq 80$ & $1(0.2)$ & 0 & $1(0.3)$ \\
\hline & & \multicolumn{3}{c}{ (Continued to the next) }
\end{tabular}

Table 1. Continued

\begin{tabular}{|c|c|c|c|}
\hline Variable & $\begin{array}{c}\text { Total } \\
(n=361)\end{array}$ & $\begin{array}{l}\text { SLBx group } \\
\quad(n=90)\end{array}$ & $\begin{array}{c}\text { ALND } \\
(n=271)\end{array}$ \\
\hline \multicolumn{4}{|l|}{ Site of breast cancer } \\
\hline Left & $166(46.0)$ & $40(44.4)$ & $126(46.5)$ \\
\hline Right & $194(53.7)$ & $50(55.6)$ & $144(53.1)$ \\
\hline Both & $1(0.3)$ & 0 & $1(0.4)$ \\
\hline \multicolumn{4}{|l|}{ Tstage } \\
\hline T1a & $14(3.9)$ & $4(4.4)$ & $10(3.7)$ \\
\hline $\mathrm{T} 1 \mathrm{~b}$ & $23(6.4)$ & $4(4.4)$ & $19(7.0)$ \\
\hline T1c & $140(38.8)$ & $38(42.2)$ & $102(37.6)$ \\
\hline $\mathrm{T} 2$ & $184(50.9)$ & 44 (48.9) & $140(51.7)$ \\
\hline \multicolumn{4}{|l|}{ N stage } \\
\hline N1mi & $94(26.0)$ & $51(56.6)$ & $43(15.9)$ \\
\hline $\mathrm{N} 1 \mathrm{a}$ & $226(62.6)$ & 38 (42.2) & $188(69.4)$ \\
\hline $\mathrm{N} 1 \mathrm{~b}$ & $5(1.4)$ & $1(1.1)$ & $4(1.5)$ \\
\hline $\mathrm{N} 2 \mathrm{a}$ & $27(7.5)$ & 0 & $27(9.9)$ \\
\hline $\mathrm{N} 3 \mathrm{a}$ & $9(2.5)$ & 0 & $9(3.3)$ \\
\hline \multicolumn{4}{|l|}{ Final stage } \\
\hline Stage IB & $28(7.8)$ & $23(25.6)$ & $5(1.8)$ \\
\hline Stage IIA & 139 (38.5) & $25(27.8)$ & $114(42.1)$ \\
\hline Stage IIB & $160(44.3)$ & $42(46.7)$ & 118 (43.5) \\
\hline Stage IIIA & $26(7.2)$ & 0 & $26(9.6)$ \\
\hline Stage IIIC & $8(2.2)$ & 0 & $8(3.0)$ \\
\hline \multicolumn{4}{|l|}{ Cell type } \\
\hline Invasive ductal carcinoma & $329(91.1)$ & 75 (83.3) & $254(93.7)$ \\
\hline Invasive lobular carcinoma & $16(4.4)$ & $8(8.9)$ & $8(2.9)$ \\
\hline Others ${ }^{a}$ & $16(4.4)$ & $7(7.8)$ & $9(3.3)$ \\
\hline \multicolumn{4}{|l|}{ Lymphatic invasion } \\
\hline Yes & $273(75.6)$ & $59(65.6)$ & $214(79.0)$ \\
\hline No & $87(24.1)$ & $31(34.4)$ & $56(20.7)$ \\
\hline Unknown & $1(0.3)$ & 0 & $1(0.4)$ \\
\hline \multicolumn{4}{|l|}{ Vascular invasion } \\
\hline Yes & $21(5.8)$ & $2(2.2)$ & $19(7.0)$ \\
\hline No & 339 (93.9) & 88 (97.8) & 251 (92.6) \\
\hline Unknown ${ }^{b)}$ & $1(0.3)$ & 0 & $1(0.4)$ \\
\hline Ki-67 (\%) & 12.06 & 8.25 & 11.91 \\
\hline \multicolumn{4}{|l|}{ Immunohistochemistry } \\
\hline Luminal A & $290(80.3)$ & $68(75.6)$ & 222 (81.9) \\
\hline Luminal B & $30(8.3)$ & $10(11.1)$ & $20(7.4)$ \\
\hline HER2-positive & $20(5.5)$ & $5(5.6)$ & $15(5.5)$ \\
\hline Triple negative & $21(5.8)$ & $7(7.8)$ & $5.2(14)$ \\
\hline $\begin{array}{l}\text { No. of receiving target } \\
\text { therapy }\end{array}$ & 38 (10.5) & $14(15.6)$ & $24(8.9)$ \\
\hline $\begin{array}{l}\text { No. of receiving hormone } \\
\text { therapy }\end{array}$ & 325 (90.0) & 80 (88.9) & 245 (90.4) \\
\hline
\end{tabular}

Values are presented as mean \pm standard deviation (range) or number (\%). SLBx, sentinel lymph node biopsy; ALND, axillary lymph node dissection; HER2, human epidermal growth factor receptor 2.

a) Eight cases of invasive cribriform carcinoma, five cases of invasive micropapillary carcinoma, three cases of mucinous carcinoma. ${ }^{b}$ Only one case, lymphatic and vascular invasion of tumor were not evaluated in pathology. 


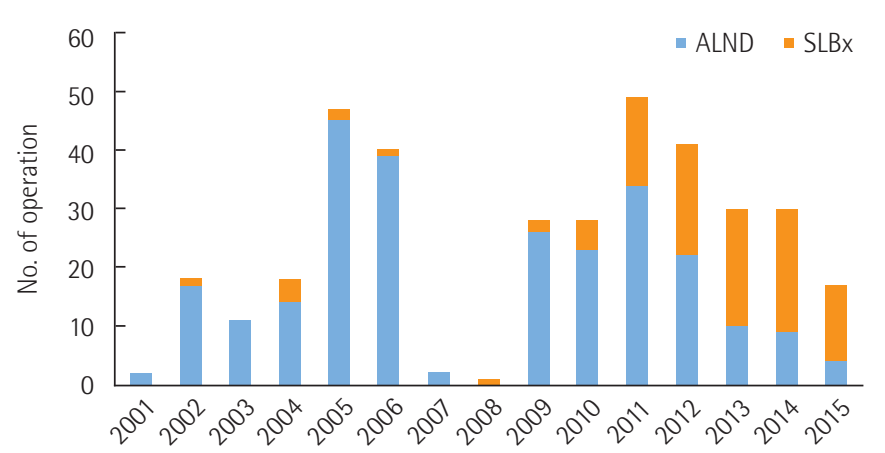

Fig. 1. Change in paradigm for axillary operation in breast cancer for 15 years. ALND, axillary lymph node dissection; SLBx, sentinel lymph node biopsy. in 2012, use of ALND rapidly decreased and lymph node sampling has replaced ALND.

\section{Surgical outcome}

Over the 15-year span that we retrospectively studied, only seven patients died from breast cancer, and there were no deaths from any other cause. Twenty-five patients experienced disease recurrence (Table 3). The SLBx group recorded no deaths and only three distant recurrences. Five-year disease-free survival rates were $96.7 \%$ in ALND group and 97.9\% in SLBx group, but there was no statistical significance $(\mathrm{P}=0.526)$ (Fig. 2).

In addition, we used logistic regression method to evaluate the association among the all patients' recurrence, total number of re-

Table 2. Lymph node status of patients

\begin{tabular}{lcccc}
\hline Lymph node status & Total $(n=361)$ & SLBx group $(n=90)$ & ALND $(n=271)$ & P-value \\
\hline Retrieval sentinel node & $2.18 \pm 1.30(1-10)$ & $2.13 \pm 1.18(1-5)$ & $2.19 \pm 1.34(1-10)$ & 0.71 \\
Positive sentinel node & $1.15 \pm 0.37(1-2)$ & $1.04 \pm 0.29(1-2)$ & $1.18 \pm 0.38(1-2)$ & 0.001 \\
Retrieved total node & $10.63 \pm 6.65(1-34)$ & $3.43 \pm 2.24(1-11)$ & $13.02 \pm 5.86(1-34)$ & 0.25 \\
Positive total node & $2.04 \pm 2.90(1-29)$ & $1.12 \pm 0.36(1-3)$ & $2.34 \pm 3.28(1-29)$ \\
Size of metastatic carcinoma $(\mathrm{mm})$ & $5.33 \pm 4.84(0.1-30.0)$ & $2.59 \pm 2.52(0.1-10)$ & $6.26 \pm 5.08(0.2-30.0)$ & 0.001 \\
\hline
\end{tabular}

Values are presented as mean \pm standard deviation (range).

SLBx, sentinel lymph node biopsy; ALND, axillary lymph node dissection.

Table 3. Death and recurrence for 15 years

\begin{tabular}{|c|c|c|c|c|}
\hline Variable & Total $(n=361)$ & SLBx group $(n=90)$ & $\operatorname{ALND}(n=271)$ & P-value \\
\hline Total period of follow-up (mo) & $94.38(17-209)$ & $69.57(40-194)$ & $101.38(17-209)$ & 0.21 \\
\hline No recurrence & $336(93.1)$ & $87(96.7)$ & 249 (91.9) & 0.08 \\
\hline Recurrence & $25(6.9)$ & $3(3.3)$ & $22(8.1)$ & 0.15 \\
\hline Locoregional & $10(2.8)$ & 0 & $10(3.7)$ & 0.06 \\
\hline Distant & $25(6.9)$ & $3(3.3)$ & $22(8.1)$ & 0.1 \\
\hline Death & $7(1.9)$ & 0 & $7(2.5)$ & 0.02 \\
\hline \multicolumn{5}{|l|}{ Locoregional recurrence site } \\
\hline Ipsilateral axilla LN & $4(1.1)$ & 0 & $4(1.5)$ & \\
\hline Ipsilateral intramammary LN & $1(0.3)$ & 0 & $1(0.3)$ & \\
\hline Ipsilateral subclavian LN & $1(0.3)$ & 0 & $1(0.3)$ & \\
\hline Remnant breast & $4(1.1)$ & 0 & $4(1.5)$ & \\
\hline \multicolumn{5}{|l|}{ Distant recurrence site ${ }^{a)}$} \\
\hline Bone & $11(3.0)$ & 0 & $11(4.0)$ & \\
\hline Lung & $13(3.6)$ & $3(3.3)$ & $10(3.7)$ & \\
\hline Liver & $6(1.6)$ & 0 & $6(2.2)$ & \\
\hline Brain & $3(0.8)$ & $1(1.1)$ & $2(0.7)$ & \\
\hline Pleura & $5(1.4)$ & 0 & $5(1.8)$ & \\
\hline Distant lymph node & $6(1.6)$ & $2(2.2)$ & $4(1.5)$ & \\
\hline Contralateral breast & $1(0.3)$ & 0 & $1(0.3)$ & \\
\hline Time to death from diagnosis (mo) & & & $61.32(31-154)$ & \\
\hline Time to death from recurrence (mo) & & & $27.33 \pm 14.55(16-55)$ & \\
\hline
\end{tabular}

Values are presented as mean (range), number (\%), or mean \pm standard deviation (range). SLBx, sentinel lymph node biopsy; ALND, axillary lymph node dissection; LN, lymph node.

${ }^{a}$ Contains cases where two or more sites of distant recurrence at the same time. 
Table 4. Multivariate logistic regression analysis of recurrence risk factors

\begin{tabular}{lcc}
\hline Risk factor & P-value & OR (95\% Cl) \\
\hline Type of axilla approach & 0.663 & $1.375(0.328-5.757)$ \\
Complications & 0.675 & $0.837(0.364-1.926)$ \\
No. of retrieval sentinel lymph node & 0.265 & $1.176(0.884-1.566)$ \\
No. of positive sentinel lymph node & 0.909 & $1.061(0.383-2.945)$ \\
No. of retrieval total lymph node & 0.085 & $1.051(0.993-1.113)$ \\
No. of positive total lymph node & 0.297 & $1.027(0.917-1.150)$ \\
$\begin{array}{l}\text { Size of metastatic carcinoma } \\
\text { of lymph node }\end{array}$ & $0.002^{\text {a) }}$ & $1.106(1.038-1.113)$ \\
\hline
\end{tabular}

$\mathrm{OR}$, odds ratio; $\mathrm{Cl}$, confidence interval.

a) $P<0.05$ was considered statistically significant.

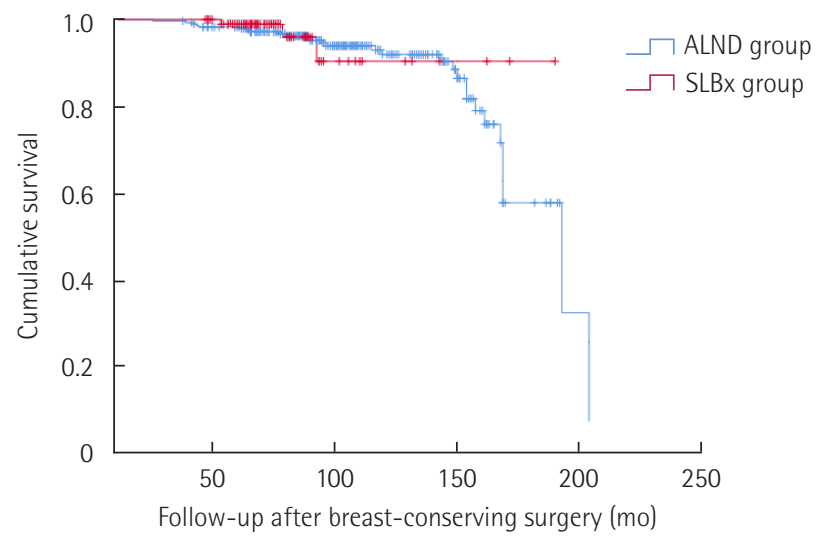

Fig. 2. Disease-free survival of both group. ALND, axillary lymph node dissection; SLBx, sentinel lymph node biopsy.

Table 5. Surgical complications

\begin{tabular}{|c|c|c|c|c|}
\hline Complications & Total $(n=361)$ & SLBx group $(n=90)$ & ALND $(n=271)$ & P-value \\
\hline Complication & & & & 0.02 \\
\hline Yes & $105(29.1)$ & $10(11.1)$ & $97(35.8)$ & \\
\hline No & 256 (70.9) & 80 (89.9) & 174 (64.2) & \\
\hline Type of complications ${ }^{\mathrm{a})}$ & & & & 0.65 \\
\hline Wound infection & $6(1.6)$ & $1(1.1)$ & $5(1.8)$ & 0.09 \\
\hline Seroma & $3(0.8)$ & 0 & $3(1.1)$ & 0.17 \\
\hline Bleeding & $1(0.3)$ & $2(2.2)$ & 0 & 0.23 \\
\hline Arm edema & $85(23.5)$ & $5(5.6)$ & $80(29.5)$ & 0.07 \\
\hline Persistent & $40(11.1)$ & $3(3.3)$ & $37(13.6)$ & \\
\hline Transient & 45 (12.5) & $2(2.2)$ & 43 (15.9) & \\
\hline Axillary web syndrome & $13(3.6)$ & $2(2.2)$ & $11(4.0)$ & 0.36 \\
\hline
\end{tabular}

Values are presented as number (\%).

SLBx, sentinel lymph node biopsy; ALND, axillary lymph node dissection.

${ }^{a}$ Contains cases where two or more complications at the same time.

trieved lymph node and metastatic lesion size of lymph node (Table 4). The greater metastatic lesion size, the higher risk of recurrence was seen $(\mathrm{P}=0.002$; odds ratio, 1.10$)$. However, the number of retrieved total lymph nodes was not correlated with recurrence $(\mathrm{P}=0.085)$.

\section{Complications}

Among patients that experienced adverse events ( $\mathrm{n}=105,29.1 \%$ ), there was a significant relationship between type of operation and complication (Table 5). The ALND group suffered from complications more than the $\operatorname{SLBx}$ group $(\mathrm{P}=0.02)$. Arm edema was the most frequent, being more common in the ALND group than SLBx group. However, the relationship between type of operation and arm edema was non-significant $(\mathrm{P}=0.07)$.

\section{DISCUSSION}

In the decade since the Z0011 trial was reported, the standard of axillary lymph node management for early breast cancer has changed to be "minimally invasive" $[8,9]$. Our institute, National Cancer Center in Korea, accepted the new guideline quickly and has applied it in the clinical field since 2012.

The primary purpose of our study was to observe how the axillary approach in the early breast cancer (cT1-2N0) changed according to new guidelines implemented in 2012 according to the Z0011 trial. Studies have shown that when the National Cancer Center began implementing a surgical approach to the management of breast cancer, every breast cancer patient received ALND if sentinel node biopsies were positive. When new guidelines were clinically applied, omission of ALND gradually increased to nearly $30 \%$ from 2012 to 2015 . To evaluate outcomes associated with the 
change in guidelines and trend in surgical approach, patients were only followed for 3 years after the application of the guidelines. Since that time, the ALND omission rate has risen much higher for patients who were clinically node-negative but confirmed to be node-positive by intraoperative frozen biopsy.

The total mean number of retrieved lymph nodes differed between ALND and SLBx groups (13.02 and 3.43 nodes, respectively). However, the final pathologic report showed no significant difference in total tumor positive nodes (2.34 and 1.12, respectively). This suggests that additional axillary node dissection may not be clinically significant. We also confirmed that the ALND group did not show improvement in local recurrence compared to the SLBx group. In the SLBx group, there were no local recurrences. Only three people had distant recurrence without local recurrence. Two had triple negative and one had HER2-positive breast cancer. One possible reason for their recurrence may be their high Ki-67 index. In one study, the application of Z0011 criteria and omission of ALND in a high-risk patients (HER2-positive/triple negative breast cancer group) was found to be safe and no one experienced recurrence [5]. The difference between the similarity in this study and our three patients in the SLBx group who experienced distant metastasis was their high Ki-67 index (median Ki-67 index: 22\% in high-risk group study vs. $65.6 \%$ in our three patients with distant metastasis). These values were much higher than the 14.3\% Ki-67 index of our entire SLBx group. The fact that high Ki-67 index is associated with a high rate of recurrence is well known from previous studies $[10,11]$.

Others have confirmed that SLBx group results in fewer wound infections and axillary seroma compared to ALND group with statistical significance [12]. In their study, lymphedema was also reported to be more common in the ALND group than in the SLBx group, although this result was not statistically significant. In our study, there were more complications associated with surgery in the ALND group than the SLBx group. Our ALND group had a higher rate of wound infections and axillary seroma compared to the SLBx group, although without statistical significance. Both persistent and transient arm edema were more common in the ALND group. Specifically, $46 \%$ of the lymphedema patients needed treatment for over 1 year in the ALND group.

Our research has clinical significance in that it is the first paper in Korea to verify the paradigm shift in axillary approach in a Z0011-eligible cohort within a single institution. However, there are some limitations to this study. First, the statistical calculation of survival and locoregional recurrence rates were not possible because there was a large difference in the number of patients between the ALND group and the SLBx group. Additionally, there were no deaths or locoregional recurrence in the SLBx group. In addition, patients receiving only SLBx were more likely to be operated on later than the ALND group. Therefore, tracking of these groups for more than 10 years may have resulted in artificially different outcomes. Second, the study retrospectively collected data on death, recurrence, and adverse events using only medical records. Third, the criterion for assessment of persistence of lymphedema of the arm was duration of the edema. The degree of edema was not included this assessment. When data on outcomes affected by new guidelines began to be collected in the early 2000s, our institute did not measure the preoperative arm circumference for all patients, eliminating the possibility of postoperative comparison of this measure.

We conclude that SLBx can be used safely in Z0011-eligible cohort without any increase of the risk of locoregional recurrence. Also, we found omission of ALND is favored to reduce some serious complications such as arm lymphedema in single-center cohort for 15 years.

\section{CONFLICT OF INTEREST}

No potential conflict of interest relevant to this article was reported.

\section{ACKNOWLEDGMENTS}

This study was supported by National Cancer Center grant NCC2010242, NCC-1810202 from the National Cancer Center, Republic of Korea.

\section{REFERENCES}

1. Giuliano AE, McCall L, Beitsch P, Whitworth PW, Blumencranz P, Leitch AM, et al. Locoregional recurrence after sentinel lymph node dissection with or without axillary dissection in patients with sentinel lymph node metastases: the American College of Surgeons Oncology Group Z0011 randomized trial. Ann Surg 2010;252:426-32.

2. Giuliano AE, Hunt KK, Ballman KV, Beitsch PD, Whitworth PW, Blumencranz PW, et al. Axillary dissection vs no axillary dissection in women with invasive breast cancer and sentinel node metastasis: a randomized clinical trial. JAMA 2011;305:569-75.

3. Giuliano AE, Ballman KV, McCall L, Beitsch PD, Brennan MB, Kelemen PR, et al. Effect of axillary dissection vs no axillary dissection on 10-year overall survival among women with invasive breast cancer and sentinel node metastasis: the ACOSOG Z0011 (Alliance) randomized clinical trial. JAMA 2017;318:918-26.

4. Tsao MW, Cornacchi SD, Hodgson N, Simunovic M, Thabane L, Cheng J, et al. A population-based study of the effects of a regional 
guideline for completion axillary lymph node dissection on axillary surgery in patients with breast cancer. Ann Surg Oncol 2016;23:3354-64.

5. Chung A, Gangi A, Mirocha J, Giuliano A. Applicability of the ACOSOG Z0011 criteria in women with high-risk node-positive breast cancer undergoing breast conserving surgery. Ann Surg Oncol 2015;22:1128-32.

6. Park HS, Chae BJ, Song BJ, Jung SS, Han W, Nam SJ, et al. Effect of axillary lymph node dissection after sentinel lymph node biopsy on overall survival in patients with T1 or T2 node-positive breast cancer: report from the Korean Breast Cancer Society. Ann Surg Oncol 2014;21:1231-6.

7. Jung J, Han W, Lee ES, Jung SY, Han JH, Noh DY, et al. Retrospectively validating the results of the ACOSOG Z0011 trial in a large Asian Z0011-eligible cohort. Breast Cancer Res Treat 2019;175:203-15.

8. Fraile M, Rull M, Julian FJ, Fuste F, Barnadas A, Llatjos M, et al. Sentinel node biopsy as a practical alternative to axillary lymph node dissection in breast cancer patients: an approach to its validity. Ann
Oncol 2000;11:701-5.

9. Samphao S, Eremin JM, El-Sheemy M, Eremin O. Management of the axilla in women with breast cancer: current clinical practice and a new selective targeted approach. Ann Surg Oncol 2008; 15:1282-96.

10. Nishimura R, Osako T, Okumura Y, Hayashi M, Toyozumi Y, Arima N. Ki-67 as a prognostic marker according to breast cancer subtype and a predictor of recurrence time in primary breast cancer. Exp Ther Med 2010;1:747-54.

11. de Azambuja E, Cardoso F, de Castro G Jr, Colozza M, Mano MS, Durbecq V, et al. Ki-67 as prognostic marker in early breast cancer: a meta-analysis of published studies involving 12,155 patients. Br J Cancer 2007;96:1504-13.

12. Lucci A, McCall LM, Beitsch PD, Whitworth PW, Reintgen DS, Blumencranz PW, et al. Surgical complications associated with sentinel lymph node dissection (SLND) plus axillary lymph node dissection compared with SLND alone in the American College of Surgeons Oncology Group Trial Z0011. J Clin Oncol 2007;25:3657-63. 